\title{
Evaluation of Antimalarial Potential of Extracts from Alstonia boonei and Carica papaya in Plasmodium berghei-Infected Mice
}

\author{
Francis O. Atanu ${ }^{D},{ }^{1}$ Favour M. Idih, ${ }^{1}$ Charles O. Nwonuma, ${ }^{2}$ Helal F. Hetta, ${ }^{3,4}$ \\ Salman Alamery, ${ }^{5}$ and Gaber El-Saber Batiha ${ }^{6}$ \\ ${ }^{1}$ Department of Biochemistry, Faculty of Natural Sciences, Kogi State University, P.M.B. 1008, Anyigba, Nigeria \\ ${ }^{2}$ Department of Biochemistry, Faculty of Pure and Applied Sciences, Landmark University, Omu-Aran, Kwara State, Nigeria \\ ${ }^{3}$ Department of Medical Microbiology and Immunology, Faculty of Medicine, Assiut University, Assiut 71515, Egypt \\ ${ }^{4}$ Department of Internal Medicine, University of Cincinnati College of Medicine, Cincinnati, OH 45267-0595, USA \\ ${ }^{5}$ Department of Biochemistry, College of Science, King Saud University, PO Box 22452, Riyadh 11451, Saudi Arabia \\ ${ }^{6}$ Department of Pharmacology and Therapeutics, Faculty of Veterinary Medicine, Damanhour University, Damanhour 22511, \\ Albeheira, Egypt
}

Correspondence should be addressed to Francis O. Atanu; atanu.fo@ksu.edu.ng

Received 31 May 2021; Revised 26 August 2021; Accepted 2 September 2021; Published 6 October 2021

Academic Editor: Hicham Harhar

Copyright (c) 2021 Francis O. Atanu et al. This is an open access article distributed under the Creative Commons Attribution License, which permits unrestricted use, distribution, and reproduction in any medium, provided the original work is properly cited.

Extracts of Alstonia boonei and Carica papaya are used in herbal medicine for the treatment of malaria. This work investigated the phytochemical, antioxidant, and antimalarial effects of hydromethanolic extracts of Alstonia boonei and Carica papaya. A four-day chemosuppressive test was conducted to assess the ability of the extracts to prevent establishment of infection. Three doses of the extracts were administered-100, 200, and $400 \mathrm{mg} / \mathrm{kg}$ bw-prior to Plasmodium berghei challenge. Change in body weight, parasitemia, packed cell volume (PCV), and mean survival time was determined. A three-day curative test was also carried out on Plasmodium berghei-infected mice to determine the effects of the plant extracts $(200 \mathrm{mg} / \mathrm{kg}$ bw) on parasitemia and biochemical indices of liver and kidney functions, lipid metabolism, and oxidative stress. The study revealed that the extracts possessed phenolic compounds ( $34.13 \pm 1.90 \mathrm{mg} \mathrm{GAE} / \mathrm{g}$ for Alstonia boonei and $27.99 \pm 1.46 \mathrm{mg}$ GAE/g for Carica papaya) and flavonoids $(19.47 \pm 1.89 \mathrm{mg}$ QE/g for Alstonia boonei and $18.24 \pm 1.36 \mathrm{mg}$ QE/g for Carica papaya). In vitro antioxidant activity measured as total antioxidant power, total reducing power, and DPPH radical scavenging activity showed that the extracts possessed higher antioxidant activity than the reference compounds. The outcome of the chemosuppressive test revealed that whereas Plasmodium bergheiinfected mice had high parasitemia, decreased mean survival time, exhibited loss of weight, and had low PCV, treatment with the extracts reversed the effects in a concentration-dependent manner. Similarly, the curative test revealed that the extracts significantly suppressed parasitemia compared with the malaria negative control group. This was mirrored by reversal of indices of hepatic toxicity (AST, ALT, and ALP levels), nephropathy (urea and creatinine levels), oxidative stress (SOD, CAT, GPx, GSH, and lipid peroxides), and dyslipidemia (TC, HDL, and TG levels and HMG-CoA reductase activity) in infected but treated mice compared with negative control. Put together, the results of this study demonstrate that the extracts of Alstonia boonei and Carica papaya possess antimalarial properties and are able to ameliorate metabolic dysregulations that characterize Plasmodium berghei infection. The phytoconstituents in these extracts are believed to be responsible for the pharmacological activity reported in this study.

\section{Introduction}

Malaria still remains a threat to life especially in children below the age of 5 in sub-Saharan Africa. According to the latest world malaria report, over 400,000 deaths were reported from over 200 million infections in 2019. The report also shows that the gains in the fight against malaria seem to have plateaued in recent times [1]. This is partly due to resistance to current frontline antimalarial drugs involving artemisininbased combination therapy and the fact that the recently licensed malaria vaccine exhibits limited efficacy. The emergence of SARS-CoV-2 causing COVID-19 infections has 
further aggravated the scourge of malaria, limiting access to malaria health care services in the WHO African region due to travel restrictions. The fact that people with febrile illness are asked to stay at home as a preventive measure against the spread of SARS-CoV-2 also limits access to malaria treatment and could lead to a rise in malaria deaths in the nearest future if not properly managed. In the light of this, there is needed to look for potent alternatives of treating malaria in sub-Saharan Africa where the global burden of the disease is highest.

Medicinal plants have been used for a very long time to treat diseases, and they continue to be a pool for the discovery of drug leads [2]. In fact, current frontline antimalarial drugs are either derived directly from plants or are synthetically produced from a plant-derived chemical compound as template. For example, artemisinin was isolated from Artemisia annua [3], while quinine was isolated from Cinchona officinalis [4]. These two compounds form the basis for artemisininbased combination therapy and the synthesis of chloroquine (or hydroxychloroquine), respectively. According to a recent review of plant-derived drugs and their contribution to the global disease pandemic, it is believed that the future of drug discovery lies in plant-derived natural products [5].

In Nigeria, folklore use of medicinal plants is a common practice due to accessibility, cultural acceptability, and relative affordability. However, this is usually at the risk of safety as most of the traditional remedies are without scientifically proven efficacy. Besides, the dosage of administration most of the time is arbitrary, increasing the risk of side effects and toxicity. One common practice among herbalists in Nigeria is the fact that these traditional remedies are derived from extraction using hydrophilic solvents such as water and ethanol. Some of the most common plants from which extracts are used as traditional remedies for diseases include Alstonia boonei, Carica papaya, Vitex doniana, Tapinanthus dodoneifolius, Senna alata, and Terminalia catappa. It is therefore expedient to study these fractions scientifically toward discovery of drug leads.

Alstonia boonei is a deciduous tree belonging to the family Apocynaceae. It can grow as high as $40 \mathrm{~m}$ and up to $27 \mathrm{~m}$ without branches [6]. Extracts from the plant have demonstrated antimalarial activities and management of anemia, which is characteristic of malaria infection. Its antimalarial activities have been examined using animal models both singly or in combination with other plants. For instance, Idowu et al. [7] showed that combination of Alstonia boonei with Picralima nitida, and Gongronema latifolium, had antiplasmodial activity with no evidence of toxicity to the liver or kidneys. A more recent study by Omoya and Oyebola [8], revealed that the leaves of Alstonia boonei had higher chemosuppressive activity than the stem extract. Extracts of Alstonia boonei have been reported to be rich in phytochemicals, which could target a plethora of plasmodium metabolic pathways.

One of such reports showed that a compound isolated from A. boonei inhibits the activity of both lactate dehydrogenase and plasmepsin II in malaria parasites [9]. Stem bark infusion of the plant has shown anticancer properties against colon cancer cell line [10] as well as antiulcerative properties [11]. Aqueous extracts of the leaf of this plant has also demonstrated anti-inflammatory and antioxidant activities in experimental rats [12].
Carica papaya is a plant commonly referred to as papaya or pawpaw. The fruit of the plant is eaten globally, while the leaves are used in some parts of the world to treat human diseases such as malaria, typhoid, piles, and diabetes. Literature search reveals scientific evidence for the antimalarial activity of C. papaya extracts when administered singly or in combination with other plant extract or with approved drugs [13-16]. C. papaya is rich in bioactive phytochemicals of diverse families. Glycosides of flavanols and caffeoyl derivatives obtained from the decoction of $C$. papaya leaves have shown synergistic potency with artesunate against $P$. falciparum and $P$. berghei, preventing parasite recrudescence [17].

However, despite the above reports, there are no available data on the antiplasmodial effect of aqueous and ethanolic extracts of the leaf of these plants to justify their use in traditional medicine for the treatment of malaria. Therefore, this study seeks to provide scientific evidence for the use of aqueous and ethanolic extracts from the leaves of these plants locally in traditional medicine. Compounds identified from the phytochemical screen can be investigated further for the discovery of potent drug leads against malaria.

\section{Materials and Methods}

2.1. Plant Collection, Identification, and Processing. Leaves of Alstonia boonei and Carica papaya were collected from Kogi State University, Anyigba, Nigeria campus, and identified in the Department of Botany by Prof. S.S. Usman. The leaves were washed with water, dried to constant weight at room temperature, and pulverized using an electric blender. The pulverized plant material was extracted in 50\% methanol $\left(\mathrm{H}_{2} \mathrm{O}\right.$ /ethanol) for 48 hours followed by filtration and concentrating of the filtrate using a rotary evaporator. The concentrated extract was allowed to evaporate to dryness. The plant extracts were stored at $4^{\circ} \mathrm{C}$.

\subsection{Phytochemical Screening of Plant Extracts}

2.2.1. Qualitative Phytochemical Screening. Phytochemical screening of the plant extracts were carried out according to methods of Trease and Evans [18] and Harborne [19].

2.2.2. Total Phenolics. The total phenolic of the extracts was determined using the Folin-Ciocalteu assay method of Singleton and Rossi [20]. The total phenolic content of the plants was then calculated and expressed as mg gallic acid equivalent (GAE)/g extract.

2.2.3. Total Flavonoids. Total flavonoid content was determined using the aluminum chloride colorimetric method by Zhilen as described by Arogba [21]. The concentrations were expressed as mg quercetin equivalent (QUE)/g extract.

\subsection{In Vitro Antioxidant Evaluation of Plant Extracts}

2.3.1. Total Antioxidant Power of Extracts. The total antioxidant power of the extracts was evaluated according to the method described by Sharifia et al. [22]. Briefly, 
concentrations ranging from 25 to $400 \mu \mathrm{g} / \mathrm{ml}$ of the extracts were prepared in DMSO. $100 \mu_{1}$ of each concentration of the extracts was mixed with $1 \mathrm{ml}$ of the working reagent $(0.6 \mathrm{M}$ sulfuric acid, $28 \mathrm{mM}$ sodium phosphate, and $4 \mathrm{mM}$ ammonium molybdate). The reaction mixture was incubated at $95^{\circ} \mathrm{C}$ for $90 \mathrm{~min}$ and then cooled, and absorbance was taken at $695 \mathrm{~nm}$ against a blank.

Vitamin $\mathrm{C}$ was used as standard. The $\mathrm{EC}_{50}$ (effective concentration) of the extracts was extrapolated from a plot of absorbance versus concentrations of each extract. The concentration that gave 0.5 absorbance was taken as the $\mathrm{EC}_{50}$.

2.3.2. Reducing Power of Extracts. The reducing power assay was performed according to the method described by Yen et al. [23]. Plant extract with concentrations ranging from 25 to $400 \mu \mathrm{g} / \mathrm{ml}$ was mixed with $2.5 \mathrm{~mL}$ of $0.2 \mathrm{M}$ phosphate buffer ( $\mathrm{pH} 6.6)$ and $2.5 \mathrm{~mL}$ of potassium ferricyanide $(1 \% \mathrm{w} /$ v). The mixture was incubated at $50^{\circ} \mathrm{C}$ for $20 \mathrm{~min}$. Then, $2.5 \mathrm{ml}$ of $1 \%$ trichloroacetic acid was added to the mixture to stop the reaction followed by centrifugation at $3000 \mathrm{rpm}$ for $10 \mathrm{~min}$. The supernatant $(2.5 \mathrm{~mL})$ was mixed with distilled water $(2.5 \mathrm{~mL})$ and $0.1 \% \mathrm{FeCl}_{3}(0.5 \mathrm{~mL})$, and then absorbance was measured at $700 \mathrm{~nm}$ against a blank.

2.3.3. DPPH Radical Scavenging Property of Extracts. The $\mathrm{DPPH}$ radical scavenging activity was evaluated according to the method of Blois [24]. $\mathrm{IC}_{50}$, which is the concentration at which $50 \%$ of the DPPH radical is scavenged, was determined from the curve of percentage inhibition plotted against various concentrations of the extracts. The results obtained were compared with the $\mathrm{IC}_{50}$ of quercetin.

\subsection{In Vivo Experiments}

2.4.1. Experimental Animals and Malaria Parasite. Male albino mice obtained from the animal house of Ahmadu Bello University, Zaria, Nigeria, were used for this study. The mice were kept in metal cages and allowed to acclimatize for the period of 14 days before been infected with the malaria parasite. Animals were fed commercial rat chow and water ad libitum throughout the period of the experiments. Animal sacrifice was humanely carried out according to acceptable international standards.
Plasmodium berghei NK65 was a gift from the Department of Parasitology, National Institute for Medical Research, Yaba, Lagos, Nigeria. The parasite was maintained in a mice host by serial passage of infected mouse to uninfected naïve mouse. The level of parasitemia was monitored by microscopic examination of blood smears.

2.4.2. Acute Toxicity Test. The acute toxicity test in both plants was carried out according to OECD no. 425 guideline as described by Habte et al. [25,26]. Male mice were fasted overnight and administered with a single oral dose of $2000 \mathrm{mg} / \mathrm{kg}$ body weight of hydroethanolic extracts of Alstonia boonei and Carica papaya. The mice were fasted for additional two hours before given food and water. The mice were thereafter observed for 24 hours. The mice were further observed for 14 days for signs of toxicity such as convulsion, aggression, loss of appetite, hair erection, and muscle tremor.

2.4.3. Induction and Monitoring of Parasitemia. Chloroquine-sensitive Plasmodium berghei NK65 strain was maintained in mice by passage of blood from infected to healthy mouse once every $4-5$ days. Induction of mouse was done by intraperitoneal injection of $200 \mu \mathrm{l}$ of blood (20-30\% parasitemia) from an infected mouse (blood collected via cardiac puncture). Parasitemia was monitored by standard methods; thin blood smears were made on glass slides, fixed using ethanol, and stained using Giemsa stain, and parasitemia was counted using a microscope and was calculated as a percentage of infected red blood cells (RBCs) relative to the total number of cells in a microscopic field at $\times 100$ magnification as given below:

$$
\text { Parasitemia }(\%)=\frac{\text { Total number of parasitise } \mathbf{d} \text { RBCs }}{\text { Total number of RBCs }} \times 100 \text {. }
$$

2.4.4. Experiment I: Suppressive Test. Mice were infected by intraperitoneal injection of parasitized blood. Treatment of the respective groups commenced $3 \mathrm{~h}$ after infection. Treatments lasted 4 days. The percentage suppression of parasitemia was calculated as below:

$$
\text { Percent Suppression }=\frac{\text { Parasitemia in negative control }- \text { Parasitemia in treate d group }}{\text { Parasitemia in negative control }} \times 100 .
$$

Mice were observed for 29 days post infection, and the mean survival time was calculated as follows:

$$
\text { Mean Survival Time }(\text { MST })=\frac{\text { Sum of survival da ys of all mice in a group }}{\text { Total number of mice in the group }}
$$


2.4.5. Experiment II: Curative Test. Mice were infected by intraperitoneal injection of parasitized blood. Treatments of the respective groups commenced $72 \mathrm{~h}$ after infection. From the results of the four-day suppressive test, a median daily dose of $200 \mathrm{mg} / \mathrm{kg}$ of the extracts was selected for the curative test. Treatments lasted 4 days.

\subsubsection{Animal Sacrifice and Collection of Blood Samples.} At the end of the experiments, mice were anesthetized using chloroform in a glass jar and blood was collected via cardiac puncture. The blood was allowed to stand on the bench for $1 \mathrm{~h}$ to clot followed by centrifugation at 5,000 rpm for $10 \mathrm{~min}$ to separate serum.

2.5. Determination of Packed Cell Volume (PCV). Packed cell volume (PCV) was determined using the capillary method. Tail blood was collected into a heparinized hematocrit tubes. The tubes were sealed with crystal seal and thereafter centrifuged for about 10,000 rpm for 5 minutes. The volume of cells was calculated according to the following formula:

$$
\mathrm{PCV}=\frac{\text { Erythrocyte volume }}{\text { Total bloo d volume }} \times 100 .
$$

2.6. Biochemical Assays. Diagnostic kits were used for the analysis of serum indices for kidney function (urea, creatinine), liver function (AST, ALT, ALP), lipid profile (HDL, TG, total cholesterol), HMG-CoA reductase, and oxidative stress markers (lipid peroxidation, catalase, superoxide dismutase, glutathione peroxidase). Assays were performed according diagnostic kits' manufacturer's protocols.

2.7. Statistical Analysis. InStat GraphPad software was used for analysis of variance (ANOVA) to ascertain significant differences between means. Differences were considered statistically significant at $P<0.05$.

\section{Results and Discussion}

Medicinal plants have been used for decades in the treatment of diseases, and they continue to be a pool for the discovery of drug leads [2]. The present study reports the antimalarial activity of Alstonia boonei and Carica papaya in P. bergheiinfected mice. This study showed that the hydroethanolic extracts of Alstonia boonei and Carica papaya contain alkaloids, flavonoids, phenolics, tannins, saponins, anthraquinones, and terpenoids (Table 1). Alkaloids, flavonoids, and tannins are known for their antioxidant, antimalarial, antimicrobial, anticancer, and anti-inflammatory activities $[27,28]$. The extracts had total phenolics $(34.13 \pm 1.90 \mathrm{mg}$ GAE/g for Alstonia boonei and $27.99 \pm 1.46 \mathrm{mg} \mathrm{GAE} / \mathrm{g}$ for Carica papaya) and total flavonoid (19.47 $\pm 1.89 \mathrm{mg} Q \mathrm{QE} / \mathrm{g}$ for Alstonia boonei and $18.24 \pm 1.36 \mathrm{mg} \mathrm{QE} / \mathrm{g}$ for Carica papaya). Phenolics have been reported to possess antioxidant, antimalarial, antimutagenic, anticancer, and anti-inflammatory capacities. The hydroxyl group substituent of aromatic benzene rings are responsible for this biological
TABLE 1: Phytochemical profile and antioxidant activity of hydroethanolic extracts of Alstonia boonei and Carica papaya.

\begin{tabular}{lcc}
\hline Parameter & Alstonia boonei & Carica papaya \\
\hline Alkaloids & + & + \\
Flavonoid & + & + \\
Phenolics & + & + \\
Tannins & + & + \\
Terpenoids & + & + \\
Saponins & + & + \\
Steroids & + & + \\
Anthraquinones & + & + \\
Cardiac glycosides & + & + \\
Extraction yield (\%) & $12.53 \pm 0.67$ & $8.10 \pm 0.56$ \\
Total phenolics (mg GAE/g) & $34.13 \pm 1.90$ & $27.99 \pm 1.46$ \\
Total flavonoid (mg QE/g) & $19.47 \pm 1.89$ & $18.24 \pm 1.36$ \\
\hline
\end{tabular}

activity due to their capacity to eliminate or absorb free radicals and to chelate reactive oxygen species molecules. The potency of phenolics is proportional to the number of hydroxyl $(\mathrm{OH})$ groups present in their aromatic rings [29]. It is believed that flavonoids exert their antimalarial activity by inhibiting fatty acid biosynthesis (FAS II) in the parasite [30,31]. Some flavonoids have also been reported to inhibit the influx of L-glutamine and myoinositol into infected erythrocytes [32].

Over the years, there have been reports validating the fact that plants do possess antioxidant activity though in varying degrees. In this study, it was observed (Figure 1) that the hydroethanolic extracts of Alstonia boonei and Carica papaya had substantial in vitro antioxidant activity almost comparable to ascorbic acid. This is not unconnected with the phytochemicals present in the extracts. The DPPH scavenging activity and TAC reported in this study also gave credence to the antioxidant activity of the extracts.

The extracts of Alstonia boonei and Carica papaya did not cause any death within the 24 hours of acute toxicity test. Furthermore, observation of the mice for 14 days did not reveal any behavioral changes characteristic of toxicity. This shows that the extract may be safe for in vivo administration up to $2000 \mathrm{mg} / \mathrm{kg}$. Our result of acute toxicity test is similar to the results of the study by Enechi et al., which showed that Alstonia boonei was tolerated up to a dose of $5000 \mathrm{mg} / \mathrm{kg}$ [33]. Similarly, Solikhah et al. reported zero death for mice administered the leaf extract of Carica papaya up to a dose of $3000 \mathrm{mg} / \mathrm{kg}$ [34].

Figures 2 and 3 show the chemosuppressive and curative antimalarial effects of the hydroethanolic extracts of Alstonia boonei and Carica papaya in Plasmodium berghei-infected mice. The extracts had a significant chemosuppressive and curative antimalarial effect on the infected mice when compared with the untreated group. This is believed to be as a result of some of the bioactive compounds such as flavonoids, phenolics, alkaloids, and anthraquinones present in the extracts [27-29]. The extracts reduced parasitemia and increased mean survival time in the treated group. It was also observed in this study (Figure 4) that though the extracts could not support increase in body weight and packed cell volume (PCV) while exerting their antimalarial effect, respectively, they were able to reduce the decreasing effect of 


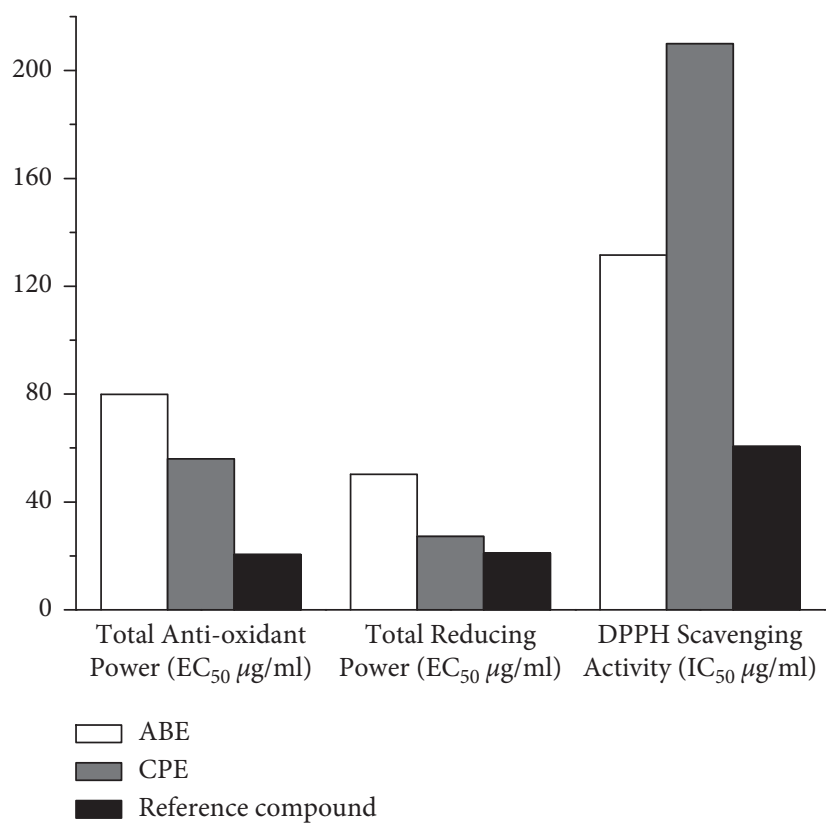

Figure 1: In vitro antioxidant screening of extracts of Alstonia boonei and Carica papaya.

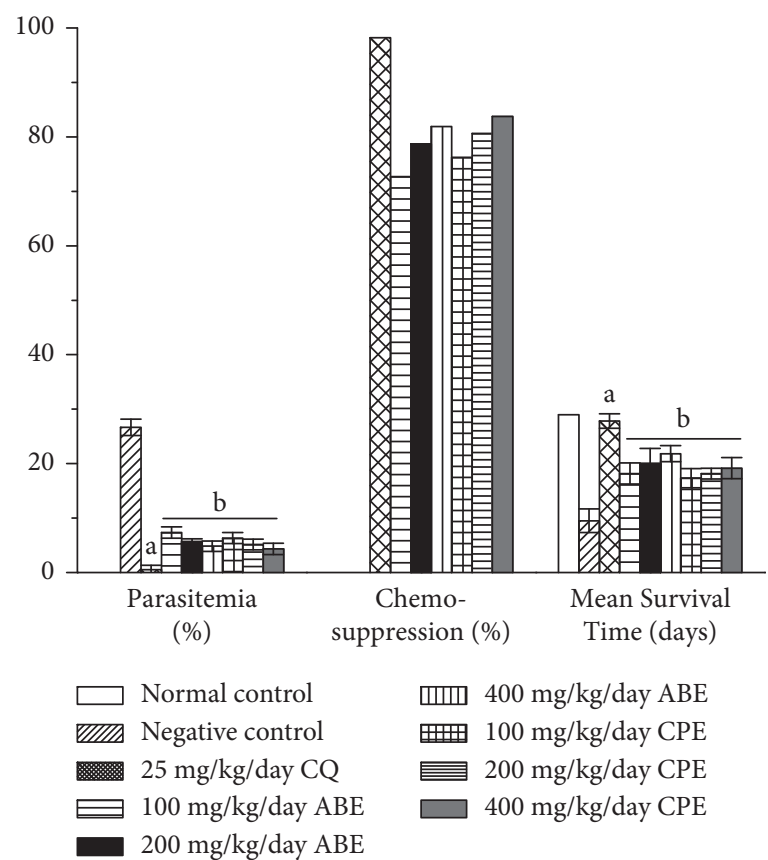

Figure 2: Chemosuppressive antimalarial effect of hydroethanolic extracts of Alstonia boonei and Carica papaya in Plasmodium bergheiinfected mice. Values are presented as mean \pm SD of six (6) determinations. $a<0.001$ compared with negative control. $b<0.001$ compared with CQ group.

the parasite on the body weight and PCV of the treated groups.

Malaria is known to cause liver and kidney damage especially is severe cases. In fact, it is the first parasitic infection to be clearly associated with glomerular diseases in the tropical region [24]. Hepatic dysfunction and jaundice are common features of severe malaria [35-37]. The extracts decreased serum AST, ALT, and ALP in the treated groups when compared with the untreated group (Figure 5); this indicates hepatoprotection. The increase in the ALP in the untreated group may be due to compromised cell membranes integrity. Similarly, the increase in the AST and ALT levels could be due to leakage from the hepatocytes due to damage by the parasite $[38,39]$. Severe malaria can lead to glomeruli disease condition as well as tubules and interstitial region disorders. It was observed in this study that the 


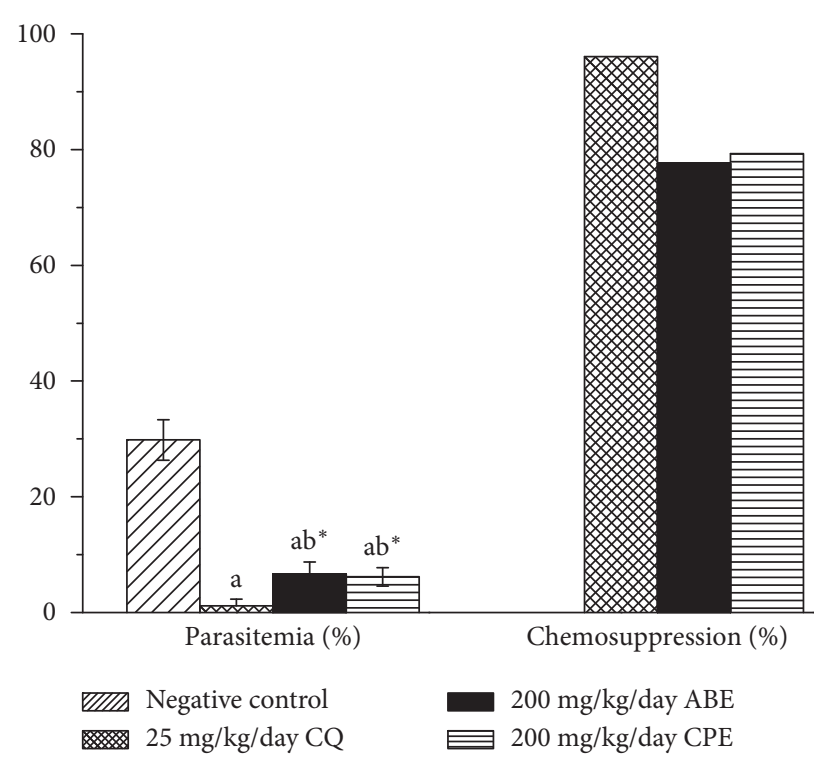

FIgURE 3: Curative antimalarial activity of hydroethanolic plant extracts of Alstonia boonei and Carica papaya in Plasmodium bergheiinfected mice. Values are presented as mean $\pm \mathrm{SD}$ of $\operatorname{six}(6)$ determinations. $a<0.001$ compared with negative control group; $b *<0.01$ compared with CQ group.

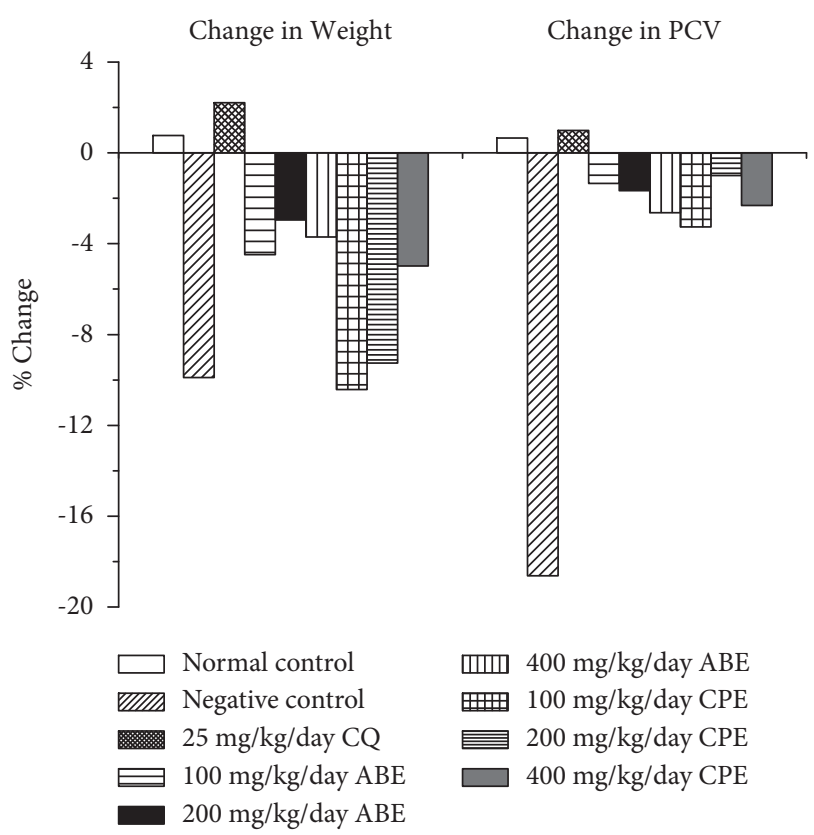

FIgURE 4: Changes in body weight and packed cell volume (PCV) in Plasmodium berghei-infected mice treated with chemosuppressive doses of hydroethanolic extracts of Alstonia boonei and Carica papaya.

extracts reduced the impact of the infection on the kidney. This is seen in the decrease of urea and creatinine (biomarkers for kidney function) in the treated groups compared with the negative untreated group (Figure 6). An alternative explanation for disturbances in urea and creatinine concentrations could be due to sequestration of the parasite into the renal microvasculature bed, which may lead to ischemia [40]. Liver and kidney diseases associated with malaria are basically as a result of erythrocyte abnormalities.
Parasitized red cells tend to adhere to healthy erythrocytes, blood platelets, and capillary endothelium, and this in turn leads to formation of rosettes and clumps, which impair microcirculation [41].

It has been hypothesized that malaria parasites use cholesterol and phospholipids from its host, resulting in a decrease of serum HDL-cholesterol [42]. This and other factors are responsible for dyslipidemia in Plasmodiuminfected animals. The result from this study showed an increase in HDL-cholesterol of the groups treated with the extracts, while a decrease in HDL-cholesterol was observed in the untreated groups (Figure 7). The fast multiplication of intrahepatic Plasmodium necessitates a high demand of lipid for organelle biogenesis [43]. In a study where microarraybased approach to profile hepatocyte response to Plasmodium infection was utilized, the results revealed upregulation of genes coding for sterol synthesis and lipid metabolism. This evidently might be responsible for the increased activity of HMG-CoA reductase activity of the pathway of cholesterol synthesis. Previous studies also reported increased concentrations in TG and VLDL and simultaneously a decrease in HDL and LDL in malarial infection condition [43]. The increase in the HDL and decrease in TG reported in the study in the treated groups could be indicative of the therapeutic potential of the extracts.

The extracts caused increased in antioxidant enzymes (SOD, catalase, GPX, and GSH) activity while decreasing lipid peroxides concentration in the treated groups; this is in contrast with the untreated group where decrease in antioxidant enzymes activity and increase in lipid peroxides were observed (Figure 8). This result correlates with what was observed in the in vitro antioxidant assay where the extracts were seen to possess substantial antioxidant activity. The increased enzyme activity is an indication of integrity or intactness of the enzyme, while the decreased activity in 


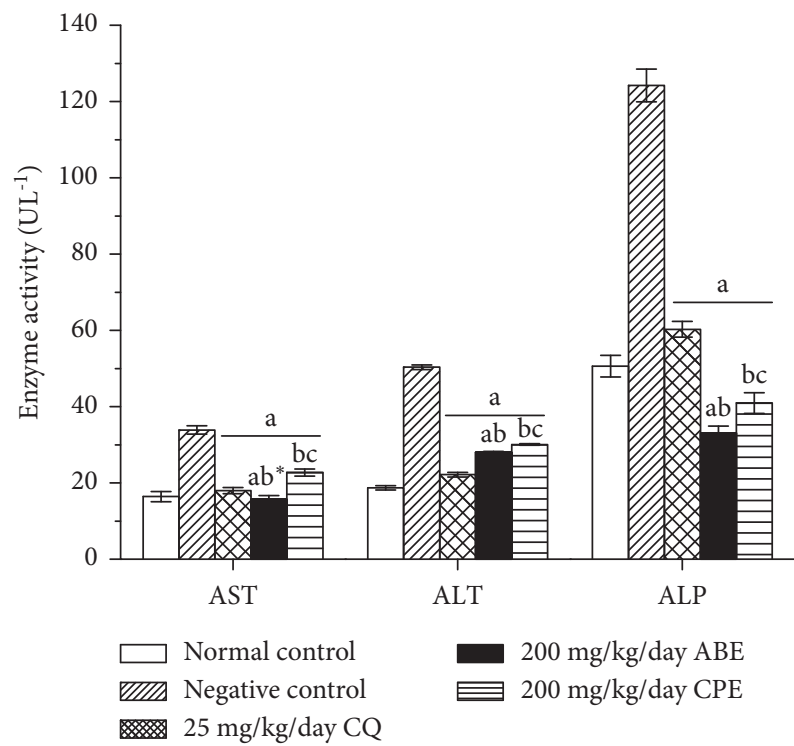

FIGURE 5: Liver function parameters of Plasmodium berghei-infected mice treated with hydroethanolic plant extracts of Alstonia boonei and Carica papaya. Values are presented as mean \pm SD of six (6) determinations. $a<0.001$ compared with negative control; $b<0.001, b *<0.01$ compared with CQ group; $c<0.001$ compared with $200 \mathrm{mg} / \mathrm{kg} /$ day ABE.

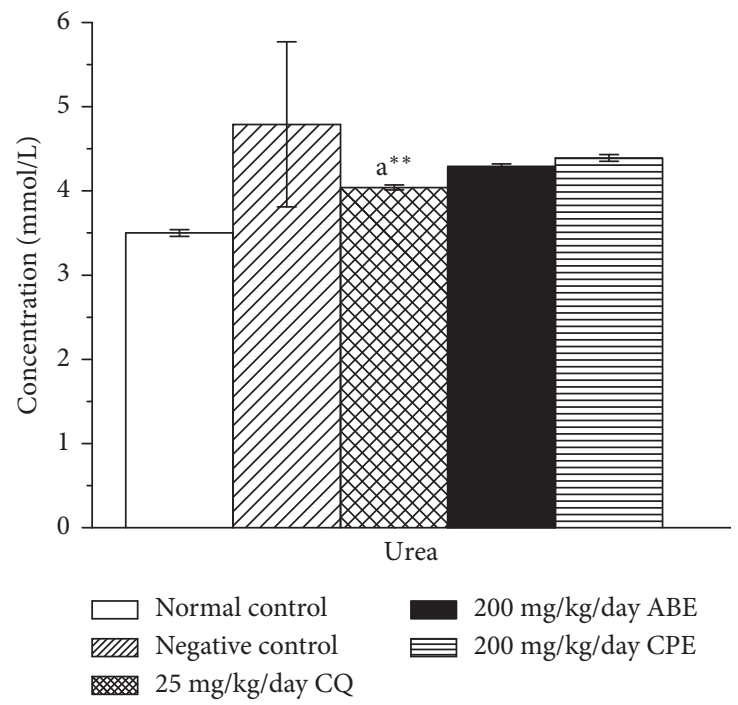

(a)

FIgURE 6: Continued. 


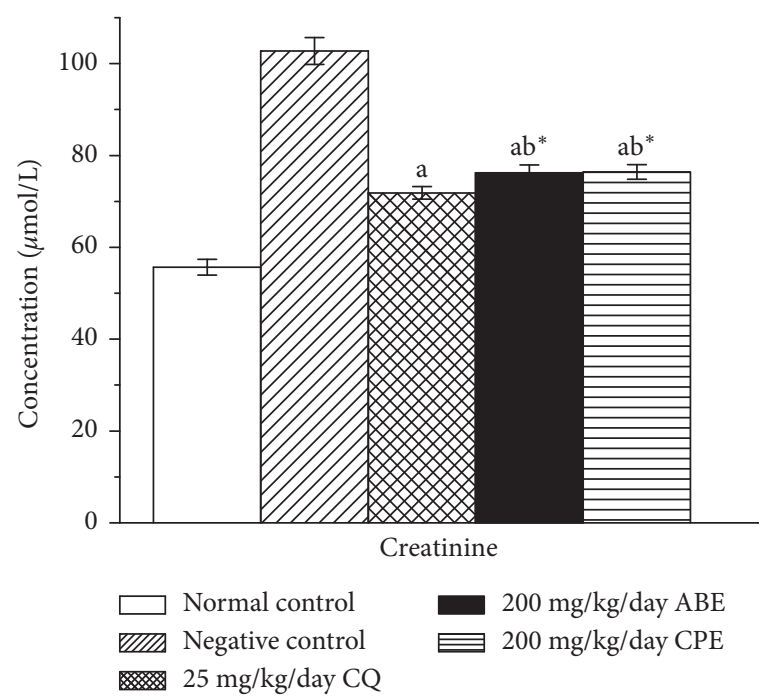

(b)

Figure 6: Kidney function parameters of Plasmodium berghei-infected mice treated with hydroethanolic plant extracts of Alstonia boonei and Carica papaya. Values are presented as mean \pm SD of six (6) determinations. $a<0.001, a * *<0.05$ compared with negative control; $b *<0.01$ compared with CQ group.

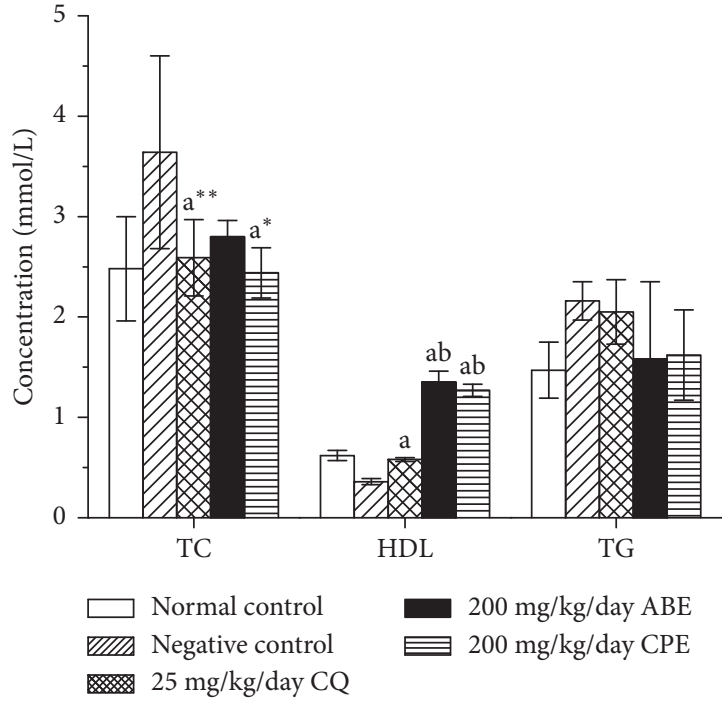

(a)

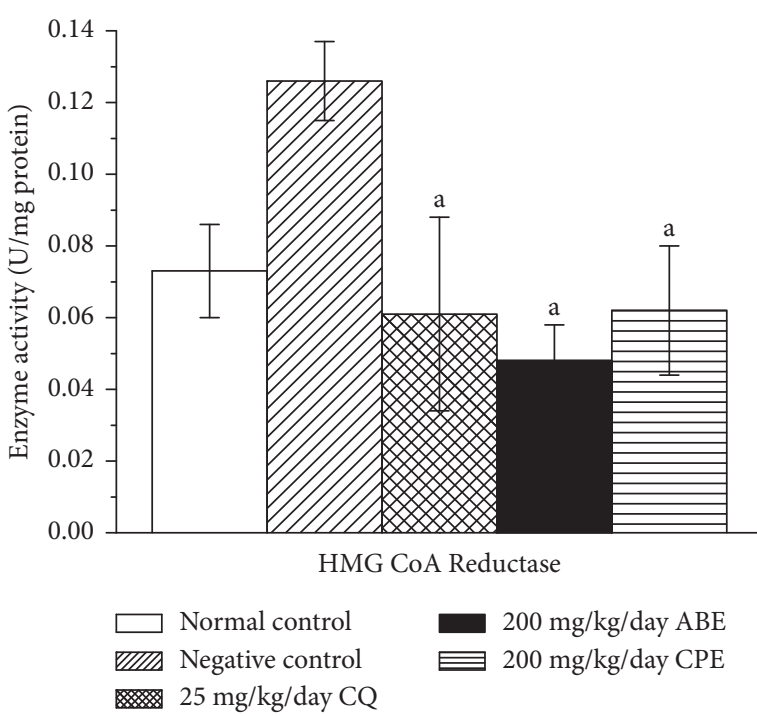

(b)

Figure 7: Lipid profile (a) and HMG-CoA reductase activity (b) of Plasmodium berghei-infected mice treated with hydroethanolic plant extracts of Alstonia boonei and Carica papaya. TC: total cholesterol, HDL: high-density lipoprotein, TG: triglycerides. Values are presented as mean \pm SD of six (6) determinations. $a<0.001, a *<0.01, a * *<0.05$ compared with negative control; $b<0.001$ compared with CQ group. 


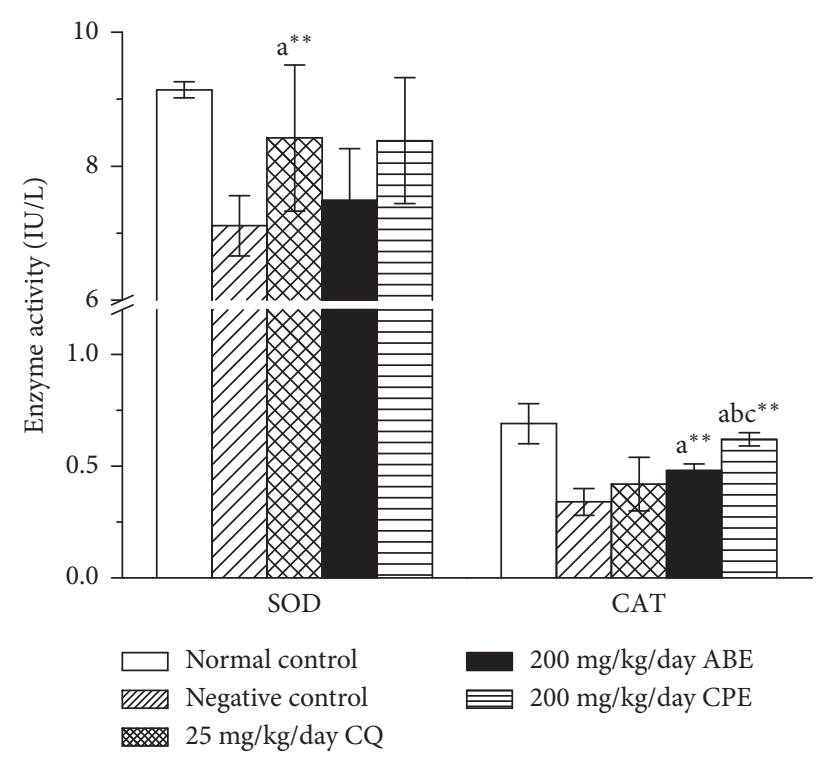

(a)

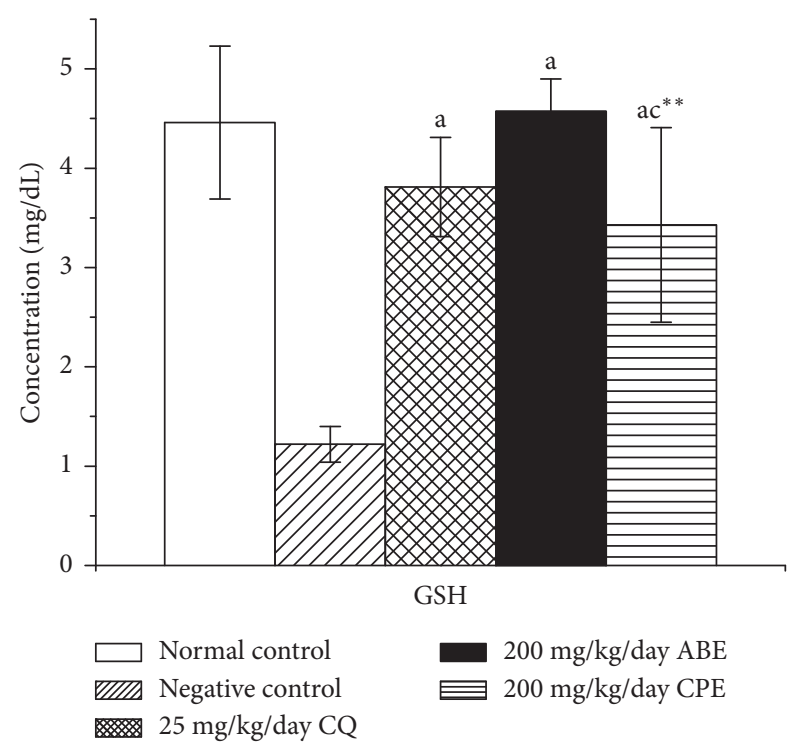

(c)

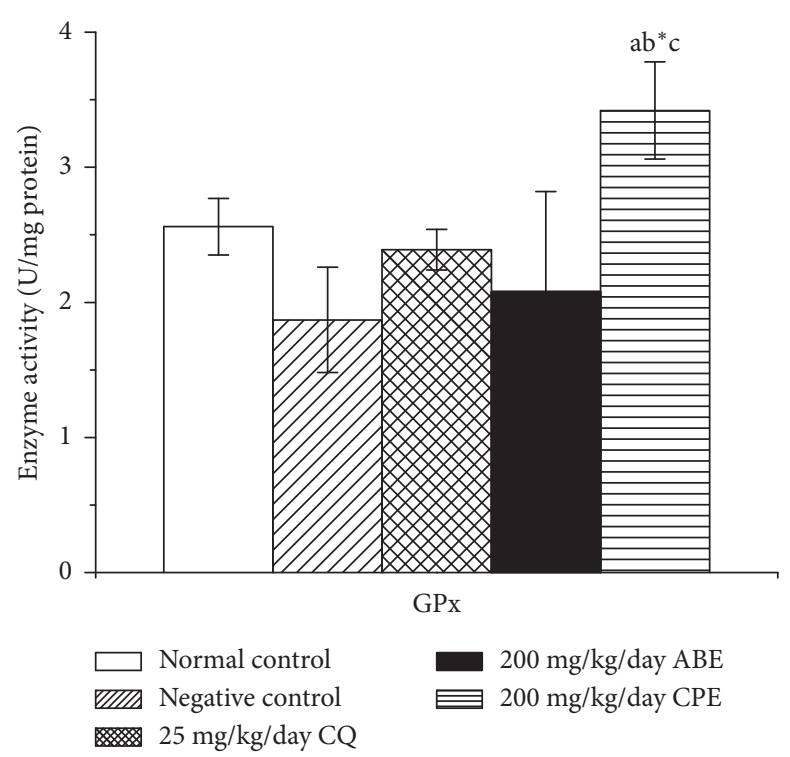

(b)

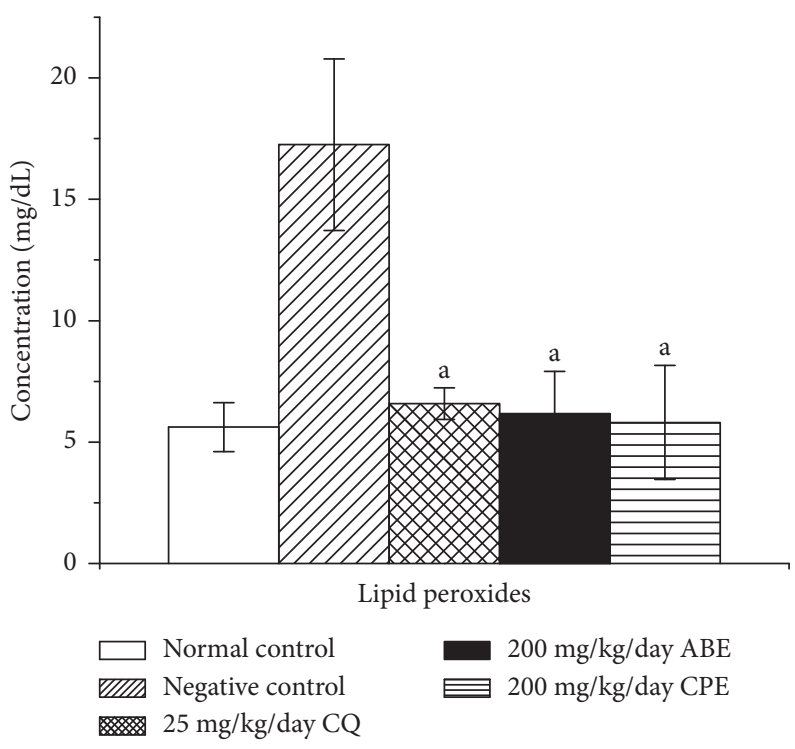

(d)

Figure 8: Oxidative stress markers of Plasmodium berghei-infected mice treated with hydroethanolic plant extracts of Alstonia boonei and Carica papaya. SOD: superoxide dismutase, CAT: catalase, GPx: glutathione peroxidase, GSH: glutathione. Values are presented as mean \pm SD of six (6) determinations. $a<0.001, a * *<0.05$ compared with negative control; $b<0.001, b *<0.05$ compared with CQ group; $c<0.001, c * *<0.05$ compared with $200 \mathrm{mg} / \mathrm{kg} /$ day ABE.

negative control group may be indicative of compromised enzyme integrity by the increased production of free radicals. The lipid peroxides level reduced while GSH levels increased significantly across the treatment groups. This result complements the ability of the extracts to increase the activity of antioxidant enzymes in parasitized mice. The decrease in peroxides and increase in GSH may be an indication of recovery from the metabolic anomalies elicited by Plasmodium infection.

Put together, phytochemicals present in hydroethanolic extracts of Alstonia boonei and Carica papaya demonstrated antimalarial activity in Plasmodium berghei-infected mice.
The extracts reversed hepatic toxicity, nephropathy, oxidative stress, and dyslipidemia in infected mice.

\section{Conclusions}

The hydroethanolic extracts of Alstonia boonei and Carica papaya possess bioactive compounds responsible for the antioxidant and antimalarial activity reported in this study. Further studies should be directed toward identifying and characterizing these bioactive active compounds for proper utilization of their potentials in disease management. 


\section{Data Availability}

All data are included in the article.

\section{Conflicts of Interest}

The authors declare no conflicts of interest.

\section{Authors' Contributions}

FOA contributed to conceptualization, funding acquisition, investigation, writing, and supervision. FMI prepared the draft and carried out study investigation; CON wrote and edited the paper and performed software analysis; $\mathrm{HFH}$ edited the paper, performed software analysis, obtained funding, and proposed methodology; SA edited the paper, performed software analysis, obtained funding, and performed experiments; and GEB obtained funding and resources and contributed to writing. All the authors have read and agreed to the published version of the manuscript.

\section{Acknowledgments}

This work was funded by the International Foundation for Science (Project number: J/5749-1) awarded to FOA. Additional support was provided by King Saud University (Project number: RSP-2020/241).

\section{References}

[1] WHO, World Malaria Report 2020, WHO, Geneva, Switzerland, 2020, https://www.who.int/publications/i/item/ 9789240015791.

[2] A. G. Atanasov, B. Waltenberger, E.-M. Pferschy-Wenzig et al., "Discovery and resupply of pharmacologically active plant-derived natural products: a review," Biotechnology Advances, vol. 33, no. 8, pp. 1582-1614, 2015.

[3] D. Klayman, "Qinghaosu (artemisinin): an antimalarial drug from China," Science, vol. 228, no. 4703, 1985.

[4] I. W. Sherman, Malaria: Parasite Biology, Pathogenesis and Protection, p. 575, ASM Press, Washington DC, USA, 1998.

[5] S. Garcia, "Pandemics and traditional plant-based remedies. A historical-botanical review in the era of COVID19," Frontiers of Plant Science, vol. 11, Article ID 571042, 2020.

[6] H. Burkill, Entry for Lasiurus Hirsutus (Forssk.) Boiss. [family POACEAE]. The Useful Plants of West Tropical Africa, Royal Botanic Gardens, Kew, UK, 2nd edition, 1985.

[7] E. T. Idowu, H. C. Ajaegbu, A. I. Omotayo, O. O Aina, and O. A Otubanjo, "In vivo anti-plasmodial activities and toxic impacts of lime extract of a combination of Picralima nitida, Alstonia boonei and Gongronema latifolium in mice infected with Chloroquine-sensitive Plasmodium berghei," African Health Sciences, vol. 15, no. 4, pp. 1262-1270, 2015, https://doi. org/10.4314/ahs.v15i4.27.

[8] F. Omoya and T. Folayele Oyebola, "Antiplasmodial activity of stem bark and leaves of Alstonia boonei (De Wild)," Journal of Microbiology \& Experimentation, vol. 7, no. 5, pp. 241-245, 2019.

[9] J. O. Olanlokun, A. F. Olotu, O. M. David, T. O. Idowu, E. M. Soliman, and O. O. Olorunsogo, "A novel compound purified from Alstonia boonei inhibits Plasmodium falciparum lactate dehydrogenase and plasmepsin II," Journal of
Biomolecular Structure and Dynamics, vol. 37, no. 8, pp. 2193-2200, 2019.

[10] A. AlQathama, U. F. Ezuruike, A. L. D. A. Mazzari, A. Yonbawi, E. Chieli, and J. M. Prieto, "Effects of selected Nigerian medicinal plants on the viability, mobility, and multidrug-resistant mechanisms in liver, colon, and skin cancer cell lines," Frontiers in Pharmacology, vol. 11, Article ID 546439, 2020.

[11] C. F. Adjouzem, A. Gilbert, M. Mbiantcha et al., "Effects of aqueous and methanolic extracts of stem bark of Alstonia boonei de wild. (Apocynaceae) on dextran sodium sulfateinduced ulcerative colitis in wistar rats," Evidence-based Complementary and Alternative Medicine, vol. 2020, Article ID 4918453, 15 pages, 2020.

[12] O. O. Akinnawo, G. s. N. Anyasor, and O. Osilesi, "Aqueous fraction of Alstonia boonei de Wild leaves suppressed inflammatory responses in carrageenan and formaldehyde induced arthritic rats," Biomedicine \& Pharmacotherapy, vol. 86, pp. 95-101, 2017.

[13] T. P. Arrey, K. D. Franzoi, S. Lee et al., "In vitro antiplasmodial activities and synergistic combinations of differential solvent extracts of the polyherbal product, nefang," BioMed Research International, vol. 83, 2014, https://doi.org/10.1155/2014/ 835013.

[14] L. O. Onaku, A. A. Attama, V. C. Okore, A. Y. Tijani, A. A. Ngene, and C. O. Esimone, "Antagonistic antimalarial properties of pawpaw leaf aqueous extract in combination with artesunic acid in Plasmodium berghei-infected mice," Journal of Vector Borne Diseases, vol. 48, no. 2, pp. 96-100, 2011.

[15] A. R. Sannella, A. Karioti, S. Orsini et al., "Leaf decoction of Carica papaya combined with artesunate prevents recrudescence in Plasmodium berghei-infected mice," Planta Medica, vol. 85, no. 11-12, pp. 934-940, 2019.

[16] O. Okpe, N. Habila, J. Ikwebe, V. A. Upev, S. I. R. Okoduwa, and O. T. Isaac, "Antimalarial potential of Carica papaya and Vernonia amygdalina in mice infected with Plasmodium berghei," Journal of Tropical Medicine, vol. 32, 2016 https:// doi.org/10.1155/2016/8738972.

[17] A. R. Sannella, A. Karioti, S. Orsini et al., "Leaf decoction of Carica papaya combined with artesunate prevents recrudescence in Plasmodium berghei-infected mice," Planta Medica, vol. 85, no. 11-12, pp. 934-940, 2019.

[18] G. E. Trease and W. C. Evans, Pharmacognosy, pp. 269-300, W.B Scandars Company Ltd., London, England, 1989.

[19] J. B. Harborne, Phytochemical Methods Guide to Modern Technique of Plant Analysis, Chapmen all Hall, London, England, 3rd Edition, 1998.

[20] V. L. Singleton and J. A. Rossi, "Colorimetry of total phenolics with phosphomolybdic-phosphotungstic acid reagents," American Journal of Enology and Viticulture, vol. 16, pp. 144-158, 1965.

[21] S. S. Arogba, "Phenolics, antiradical assay and cytotoxicity of processed mango (Mangifera indica) and bush mango (Irvingia gabonensis) kernels," Nigerian Food Journal, vol. 32, no. 1, pp. 62-72, 2014.

[22] B. Sharifia, S. A. H. Goli, and Y. Maghsoudlou, "Antioxidant activity and chemical composition of the methanolic extract and related fractions of Dracocephalum kotschyi leaves using liquid chromatography-tandem mass spectrometry," Industrial Crops and Products, vol. 104, pp. 111-119, 2017.

[23] G.-C. Yen and H.-Y. Chen, "Antioxidant activity of various tea extracts in relation to their antimutagenicity," Journal of 
Agricultural and Food Chemistry, vol. 43, no. 1, pp. 27-32, 1995.

[24] M. S. Blois, "Antioxidant determinations by the use of a stable free radical," Nature, vol. 181, no. 4617, pp. 1199-1200, 1958, https://doi.org/10.1038/1811199a0.

[25] G. Habte, T. Nedi, and S. Assefa, "Antimalarial activity of aqueous and $80 \%$ methanol crude seed extracts and solvent fractions of Schinus molle linnaeus (anacardiaceae) in Plasmodium berghei-infected mice," Journal of Tropical Medicine, vol. 9473250, 2020, https://doi.org/10.1155.

[26] Organization of Economic Co-operation and Development (OECD), Guidelines for Testing of Chemicals: Guideline 425: Acute Oral Toxicity, Organization of Economic Co-operation and Development (OECD), Paris, France, 2008.

[27] P. Amoa Onguéné, F. Ntie-Kang, L. L. Lifongo, J. C. Ndom, W. Sippl, and L. M. a. Mbaze, "The potential of anti-malarial compounds derived from African medicinal plants. Part I: a pharmacological evaluation of alkaloids and terpenoids," Malaria Journal, vol. 12, no. 1, p. 449, 2013.

[28] A. L. Gollo, V. O. A. Tanobe, G. V. de Melo Pereira et al., "Phytochemical analysis and biological activities of in vitro cultured Nidularium procerum, a bromeliad vulnerable to extinction," Science Report, vol. 10, no. 7008, 2020, https://doi. org/10.1038/s41598-020-64026-z.

[29] L. A. R. D. O. Macêdo, R. G. d. Oliveira Júnior, G. R. Souza et al., "Chemical composition, antioxidant and antibacterial activities and evaluation of cytotoxicity of the fractions obtained fromSelaginella convoluta(Arn.) Spring (Selaginellaceae)," Biotechnology \& Biotechnological Equipment, vol. 32, no. 2, pp. 506-512, 2018.

[30] R. Perozzo, M. Kuo, A. b. S. Sidhu et al., "Structural elucidation of the specificity of the antibacterial agent triclosan for malarial enoyl acyl carrier protein reductase," Journal of Biological Chemistry, vol. 277, no. 15, pp. 13106-13114, 2002.

[31] J. S. Freundlich, M. Yu, E. Lucumi et al., "Synthesis and biological activity of diaryl ether inhibitors of malarial enoyl acyl carrier protein reductase. Part 2: 2'-Substituted triclosan derivatives," Bioorganic \& Medicinal Chemistry Letters, vol. 16, no. 16, pp. 2163-2169, 2006.

[32] B. C. Elford, "l-Glutamine influx in malaria-infected erythrocytes: a Target for antimalarials?" Parasitology Today, vol. 2, no. 11, pp. 309-312, 1986.

[33] O. C. Enechi, I. H. Oluka, and O. P. C. Ugwu, "Acute toxicity, lipid peroxidation and ameliorative properties of Alstonia boonei ethanol leaf extract on the kidney markers of alloxan induced diabetic rats," African Journal of Biotechnology, vol. 13, no. 5, pp. 678-682, 2014.

[34] T. I. Solikhah, B. Setiawan, and D. R. Ismukada, "Antidiabetic activity of papaya leaf extract (Carica papaya L.) isolated with maceration method in alloxan induces diabetic mice," Systematic Reviews in Pharmacy, vol. 11, no. 9, pp. 774-778, 2020.

[35] H. M. Elsheikha and H. A. Sheashaa, "Epidemiology, pathophysiology, management and outcome of renal dysfunction associated with plasmodia infection," Parasitology Research, vol. 101, no. 5, pp. 1183-1190, 2007.

[36] A. Jain, R. Kaushik, and R. M. Kaushik, "Malarial hepatopathy: clinical profile and association with other malarial complications," Acta Tropica, vol. 159, pp. 95-105, 2016.

[37] N. Kaeley, S. Ahmad, N. Shirazi et al., "Malarial hepatopathy: a 6-year retrospective observational study from Uttarakhand, North India," Transactions of The Royal Society of Tropical Medicine and Hygiene, vol. 111, no. 5, pp. 220-225, 2017.

[38] I. Onyesom and N. Onyemakonor, "Levels of parasitaemia and changes in some liver enzymes among malarial infected patients in Edo-Delta Region of Nigeria," Current Research Journal of Biological Sciences, vol. 3, no. 2, pp. 78-81, 2011.

[39] O. M. Akanbi, "The influence of malaria infection on kidney and liver function in children in Akoko area of Ondo state, Nigeria," Journal of Parasitology and Vector Biology, vol. 7, no. 8, pp. 163-168, 2015.

[40] H. Y. Zaki, B. E. Abdalla, and B. Hayder, "Biochemical Profiles of Children with Severe Plasmodium falciparum malaria in central Sudan: a case control study," Al Neelain Medical Journal, vol. 3, pp. 15-23, 2013.

[41] R. S. Barsoum, "Malarial acute renal failure," Journal of the American Society of Nephrology, vol. 11, no. 11, pp. 2147-2154, Article ID 11053494, 2000.

[42] B. J. Visser, R. W. Wieten, I. M. Nagel, and M. P. Grobusch, "Serum lipids and lipoproteins in malaria - a systematic review and meta-analysis," Malaria Journal, vol. 12, no. 1, Article ID 442, 2013.

[43] M. Labaied, B. Jayabalasingham, N. Bano et al., "Plasmodium salvages cholesterol internalized by LDL and synthesized de novo in the liver," Cellular Microbiology, vol. 13, no. 4, pp. 569-586, 2011. 